\title{
Inteligência Empresarial: Um Novo Modelo de Gestão para a Nova Economia
}

\author{
Marcos Cavalcanti \\ COPPE/UFRJ \\ Professor Adjunto da COPPE/UFRJ \\ Doutor em Informática pela Université de Paris XI \\ CRIE - Centro de Referência em Inteligência Empresarial \\ Area de Inovação Tecnológica e Organização Industrial \\ Programa de Engenharia de Produção \\ marcos@crie.coppe.ufrj.br

\section{Elisabeth Gomes} \\ CNEN/DPD \\ Assessora da Diretoria de P\&D \\ MSc em Engenharia Nuclear pela COPPE/UFRJ \\ Doutoranda em Engenharia de Produção na COPPE/UFRJ-ITOI \\ Comissão Nacional de Energia Nuclear \\ Diretoria de Pesquisa e Desenvolvimento \\ betgomes@cnen.gov.br
}

\section{Resumo}

Neste artigo, apresentamos a idéia de que os modelos econômicos, baseados nos três fatores tradicionais de produção devem ser revistos no sentido de incorporar o Conhecimento como fator essencial da produção econômica. A partir deste re Conhecimento, propomos um novo modelo para a gestão de negócios na Sociedade do Conhecimento: a Inteligência Empresarial, e apresentamos um modelo para a gestão dos capitais do Conhecimento. Apresentamos e discutimos, ainda, algumas idéias de como o Brasil deve se posicionar nessa nova economia.

Palavras-chave: inteligência empresarial, gestão do conhecimento, inovação e empreendedorismo

\section{Abstract}

In the present article we introduce the idea that the economical models, based upon the three traditional production factors, should be revised regarding the incorporation of the Knowledge as an essential instrument of the economical production itself. Through the necessary recognition of this point-of-view, we propose a new concept for the business administration in the Knowledge Society: the Enterprise Intelligence, and we introduce, as well, a model for the management of the Knowledge capital. We also suggest and would like to discuss a few ideas of how developing countries like Brazil should position itself on this new Economics.

Keywords: enterprising intelligence, knowledge management, business innovation and enterpreneurship

\section{Introdução}

A economia do Conhecimento desloca o eixo da riqueza e do desenvolvimento de setores industriais tradicionais - intensivos em mão-de-obra, matéria-prima e capital - para setores cujos produtos, processos e serviços são intensivos em tecnologia e conhecimento. Mesmo na agricultura e na indústria de bens de consumo e de capital, a competição é cada vez mais baseada na capacidade de transformar informação em Conhecimento e Conhecimento em decisões e ações de negócio. O valor dos produtos depende, assim, cada vez mais, do percentual de inovação, tecnologia e inteligência a eles incorporados.

Se antes o que gerava riqueza e poder eram os 
PRODUÇÃO

fatores de produção tradicionais - capital, terra e trabalho hoje, segundo o Banco Mundial, 64\% da riqueza mundial advém do Conhecimento ${ }^{1}$.

Tais mudanças ocasionam um profundo impacto na economia do país e na vida de milhões de brasileiros.

Podem configurar-se como ameaça, se nos acomodarmos no papel atual de país consumidor de produtos intensivos em Conhecimento, ou como oportunidade por desestabilizar o equilíbrio vigente, permitindo que novos atores explorem os espaços criados e se destaquem no cenário mundial.

Neste artigo, defendemos a idéia de que os modelos econômicos baseados nos três fatores tradicionais de produção devem ser revistos no sentido de incorporar o Conhecimento como fator essencial da produção econômica. A partir deste reConhecimento, propomos um novo modelo para a gestão de negócios na Sociedade do Conhecimento: a Inteligência Empresarial, e apresentamos um modelo para a gestão dos capitais do Conhecimento.

Na seção seguinte, apresentaremos uma rápida caracterização do Conhecimento e da evolução do seu significado ao longo do tempo para, na seção 3 , mostrarmos como o Conhecimento é o novo motor da Economia. Mas, se o Conhecimento é tão importante, precisamos saber gerenciá-lo eficazmente. Na seção 4 apresentamos/apresentaremos um modelo que nos diz como fazer isto; a seção 5 descreve a maneira como achamos que o Brasil pode se inserir nesta Sociedade e concluímos pela apresentação das idéias centrais do artigo.

\section{Terra, Capital, Trabalho e CONHECIMENTO}

Peter Drucker (1993), no seu livro Post-capitalist Society, afirma que a "questão central para o executivo moderno é ser capaz de usar o Conhecimento para criar novos produtos e serviços". Mas, de que Conhecimento ele está falando? E qual a relação entre Conhecimento e tecnologia?
Desde a Grécia antiga existem diferentes visões sobre o significado e a função do Conhecimento, tanto no ocidente/Ocidente como no oriente/Oriente. Sócrates e os monges Taoístas e Zen acreditavam que a única função do Conhecimento era o auto-Conhecimento, e que ele deve/ devia ser usado para o crescimento pessoal, para aumentar nossa auto-satisfação/auto-estima e sabedoria. Confucius, no Oriente, e Protágora (oponente de Sócrates), no Ocidente, acreditavam que o propósito do Conhecimento era fazer com que a pessoa soubesse o que dizer e como dizer. Para Protágoras, isto significava lidar com a lógica, gramática e retórica, base/bases de toda a educação ocidental.

Muito se falou sobre o Conhecimento ${ }^{2}$, sem que se chegasse a um consenso sobre sua melhor definição. $\mathrm{Na}$ verdade, o Conhecimento é algo que alguém pode absorver somente com o aprendizado e a experiência. Difícil de ser explicitado, ele pode, no entanto, ser demonstrado. Ele é técnica - do grego téchne - algo com uma aplicação específica, sem princípios gerais, sem uma formalização $o^{3}$.

As primeiras tentativas de sistematização do Conhecimento vieram da Europa: a primeira Escola de Engenheiros foi fundada na França em 1747, École des Ponts et Chaussés, logo seguida pela Ecole/École Polytechnique, em 1794. Na Alemanha, a primeira Escola de Agricultura foi fundada em 1770. Simultaneamente, um dos mais importantes livros da história, a Enciclopédia, foi editado entre 1751 e 1772 por Denis Diderot e Jean D'Alembert. Eles almejavam reunir todas as tecnologias existentes de forma que estas pudessem ser aprendidas por "tecnologistas". Tecnologia é a combinação de téchne (Conhecimento) com logy (organizado, sistematizado). O termo surgiu, portanto, durante o século XVIII, a partir do movimento de criação das Escolas e das tentativas de sistematização do Conhecimento.

O que estas novas Escolas e a Enciclopédia estavam fazendo era converter experiência em Conhecimento, gerando receitas de como fazer as coisas, criando metodologias. A tecnologia modificou, desta forma, o significado do Conhecimento. Ela levou a téchne mais longe, mostrando que esse Conhecimento específico 
poderia ser generalizado em torno de princípios gerais e que isto poderia ser ensinado e aprendido por outras pessoas. Em suma, a tecnologia possibilitou a aplicação e o uso do Conhecimento.

Mas quando foi que o Conhecimento e a tecnologia passaram a ter uma importância econômica?

Desde Adam Smith que diferentes correntes do pensamento econômico concordam que os fatores de produção são terra, capital e trabalho. Esta classificação teve um profundo impacto no processo de desenvolvimento da Economia, enquanto Ciência e marcou o pensamento de gerações de economistas ${ }^{4}$. Este impacto foi tão grande que mais de duzentos anos depois, as Faculdades de Economia em todo o mundo continuam adotando textos que utilizam estes mesmos conceitos, baseados em processos produtivos e estruturas de classe do século XVIII.

Ao se estudar as economias de natureza agrícola, percebe-se que a terra e a mão-de-obra eram os fatores críticos para determinar o sucesso econômico. Claro que o capital e a tecnologia (o arado, por exemplo) eram importantes, mas a comunidade agrícola podia subsistir com um mínimo de dinheiro e tecnologia, porém não sem terra e mão-de-obra. Com a revolução industrial, a tecnologia ganha importância, mas o capital e o trabalho passam a ser as forças motrizes do desenvolvimento econômico.

Uma nova realidade, no entanto, vem se impondo no cenário mundial: a chamada Sociedade do Conhecimento. Peter Drucker, já em 1968, enfatizava que “o

Conhecimento tornou-se o recurso essencial da economia”. Em seu livro "Post-Capitalist Society" (1993), ele afirma que "o fator decisivo de produção é o Conhecimento".

Em resumo, na nova Economia, os modelos econômicos baseados nos três fatores de produção tradicionais precisam ser revistos no sentido de incorporar o Conhecimento, não apenas como mais um fator de produção, mas como fator essencial do processo de produção e geração de riqueza. Os fatores de produção tradicionais não deixarão de existir, mas poderão ser obtidos com alguma facilidade desde que tenhamos Conhecimento.

\section{Conhecimento: o Novo Fator de Produção}

Relatório da OECD aponta que, em 1998, mais de $50 \%$ do PIB dos países desenvolvidos devia-se ao uso do Conhecimento $^{5}$ O relatório destaca, ainda, que a crescente redução dos custos e a facilidade de obtenção da informação apontam, claramente, para um aumento da participação do Conhecimento na geração de riqueza para organizações, regiões e países.

Como conseqüência direta deste papel de destaque do Conhecimento, assistimos uma crescente procura por profissionais mais qualificados. Este relatório mostra que o desemprego entre as pessoas que têm até o segundo grau é de 10,5\%, em média, nos países da OECD, caindo para $3,8 \%$ entre aqueles com educação universitária. $\mathrm{O}$ estudo mostra ainda que, ao mesmo tempo que o emprego no setor industrial vem caindo, ele vem aumentando rapidamente em setores de alta tecnologia como Telecomunicações, Informática, farmácia e no setor de serviços.

\section{o Conhecimento é, portanto, o novo motor da} economia.

Lidar com este novo fator de produção é uma novidade; formular uma nova teoria econômica para lidar com ele, é um desafio. No entanto, podemos afirmar que necessitamos desta nova teoria para colocar o Conhecimento no centro do processo de geração de riqueza.

\section{A Inteligência Empresarial}

Quando Drucker começou a estudar gestão de empresas, logo após a II Grande Guerra, um administrador era definido como "alguém que é responsável pelo trabalho e por seus subordinados". Em suma: o "patrão", ou o "chefe". Hoje, Drucker sugere que esta definição mude para alguém que "é responsável pela aplicação e desempenho do Conhecimento". Isto significa que a gestão passa, hoje, por usar o Conhecimento existente na organização para gerar melhores resultados. Os grandes ganhos de produtividade, daqui para frente, advirão das melhorias na gestão do Conhecimento. 
PRODUÇÃO

A produtividade do Conhecimento deve ser, portanto, a preocupação central dos administradores do século XXI. No entanto, o Conhecimento só será produtivo se gerenciarmos toda sua cadeia de valor/valores.

As empresas querem ser produtivas para serem mais lucrativas. E lucratividade e competitividade são as verdadeiras determinantes da inovação tecnológica e do crescimento da produtividade. Assim, não podemos nos contentar em gerar novos Conhecimentos, em fazer apenas a pesquisa pela pesquisa, ou simplesmente em coletar informações e guardá-las. Sem capacidade de inovar - criar novos produtos e serviços - mas também, de criar novos mercados, exportar e empreender negócios, nenhuma empresa se tornará líder em seu setor ou mesmo conseguirá sobreviver nesta economia globalizada.

Conhecimento, inovação e empreendedorismo formam, assim, um tripé indissociável (figura 1) para o sucesso das organizações na nova Economia. A esta sinergia entre Conhecimento, inovação e empreendimento damos o nome de Inteligência Empresarial.

Neste artigo, não falaremos sobre inovação e o empreendedorismo. O modelo de gestão que iremos apresentar a seguir tem seu foco na gestão do Conhecimento. Alertamos, no entanto, que o sucesso das organizações do século XXI dependerá de sua habilidade em aplicar na prática o modelo de Inteligência Empresarial.
4.1 Modelos de Gestão do Conhecimento

Diversos autores perceberam a importância econômica do Conhecimento como fator de produção e propuseram modelos de gestão do Conhecimento. Sveiby (1998), Stewart (1998) e Edvinsson (1998), os pioneiros da Gestão do Conhecimento, eram empresários e jornalistas. Para estes autores, o valor de empresas intensivas/onde o Conhecimento abunda, deixou de estar relacionado aos bens tangíveis, como prédios e máquinas, passando a ser cotado a partir de seus ativos intangíveis.

Todos os três propõem um modelo de gestão para as empresas, formado por três componentes básicos. O primeiro deles, Sveiby nomeia estrutura interna; Stewart chama de capital estrutural e Edvinsonn de capital organizacional. Eles estão se referindo às patentes, conceitos e modelos administrativos e informatizados de uma organização. O segundo capital é o que Sveiby chama de competências enquanto que Stewart e Edvinsonn chamam de capital humano. Este capital tem a ver com a capacidade individual de atuação de cada integrante da empresa. Nesta categoria, estão incluídas as habilidades, a educação formal, a experiência e os valores de um determinado indivíduo. Finalmente, o terceiro capital é chamado de estrutura externa por Sveiby e de capital de clientes por Stewart e Edvinsonn. Neste último se

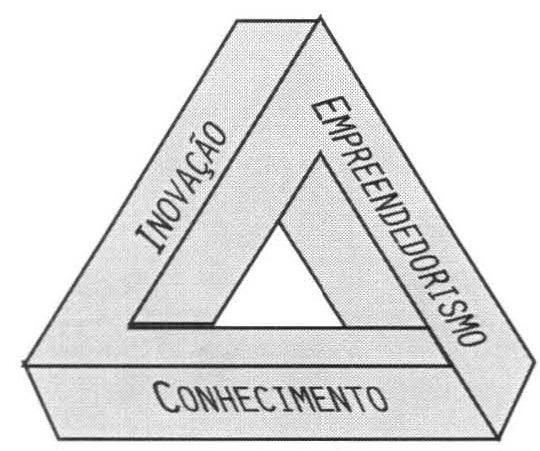

Figura 1. Inteligência empresarial: a gestão da nova economia ${ }^{6}$ 
inscrevem os clientes, parceiros, fornecedores e a imagem que a empresa tem junto a eles e ao mercado.

Todos os modelos apresentados coincidem num ponto: monitorar e gerenciar a informação e o Conhecimento é uma tarefa essencial para todas as pessoas e organizações desejosas de competir num mundo cada vez mais globalizado. Os três modelos analisados não são, obviamente, contraditórios.

O modelo de gestão para empresas na Sociedade do Conhecimento que apresentamos a seguir, denominado Capitais do Conhecimento, é fruto de reflexão teórica e de observação prática sobre a questão. Teoricamente, é baseado nos conceitos expostos por Sveiby, Edvinsson e Stewart; empiricamente, é fundamentado em experiências concretas desenvolvidas por alguns projetos de gestão do Conhecimento levados a cabo, desde início de 1998, pelo Centro de Referência em Inteligência Empresarial da Universidade Federal do Rio de Janeiro (CRIE/COPPE/UFRJ).

\subsection{Os Capitais do Conhecimento®}

\section{O modelo dos Capitais/Bens do/de Conhecimento} apresenta quatro capitais que devem ser devidamente monitorados e gerenciados para uma efetiva gestão do Conhecimento de uma organização. São eles: o "capital ambiental", o "capital estrutural", o "capital intelectual" e “capital de relacionamento" (Fig. 2).

Na realidade não existe, a priori, um capital mais importante do que o outro. A importância relativa entre os quatro capitais depende de cada organização, seu grau de desenvolvimento e do tipo de negócio em que ela está envolvida. O crescimento de uma empresa depende da sinergia entre esses capitais.

Por exemplo: uma jovem empresa incubada normalmente tem alto capital intelectual e baixo capital estrutural e de relacionamento. Para crescer, necessita desenvolver estes capitais. Cada empresa precisa analisar sua situação para definir sua estratégia de Conhecimento.

\subsubsection{Capital Ambiental}

O capital ambiental é o primeiro dos quatro capitais. Ele é definido como o conjunto de fatores que descrevem o ambiente onde a organização está inserida. Estes fatores são expressos pelo conjunto das características sócioeconômicas da região (nível de escolaridade, distribuição de renda, taxa de natalidade, etc), pelos aspectos legais, valores éticos e culturais, pelos aspectos governamentais (grau de participação do governo, estabilidade política) e pelos aspectos financeiros, como o nível de taxa de juros e os

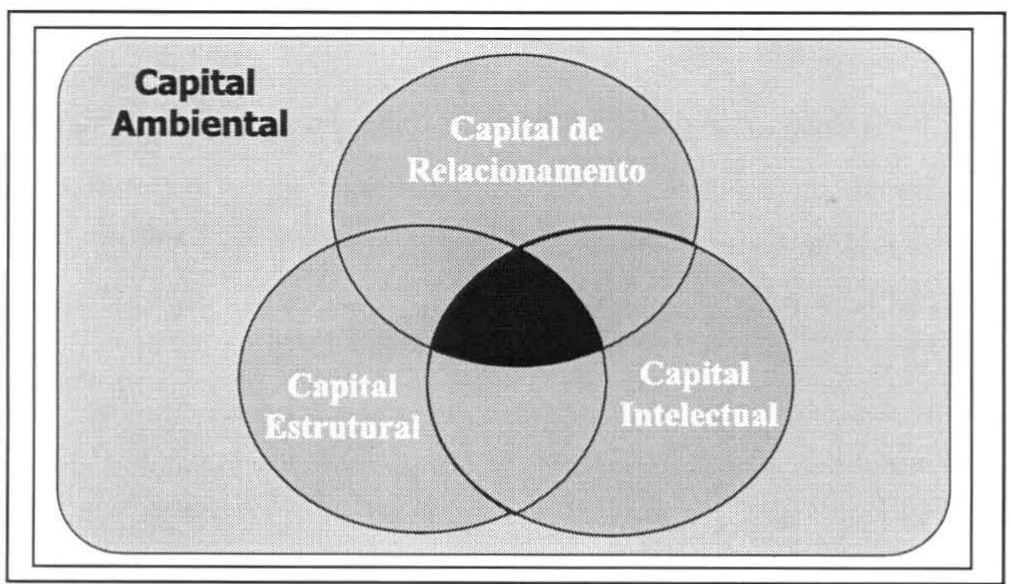

Fonte: Centro de Referência em Inteligência Empresarial CRIE - COPPE/UFRJ

Figura 2. Os capitais do conhecimento® 
PRODUÇÃO

mecanismos adequados de financiamento.

Nenhuma organização pode existir sem saber onde está nem aonde quer chegar, o que significa ter uma definição muito clara da sua visão estratégica e do seu posicionamento no mercado. Além disso, é indispensável estar atento às mudanças, ser flexível, perceber as inovações tecnológicas e, principalmente, entender que informação e Conhecimento são fatores estratégicos. E ainda, que a definição do segmento de atuação, a perseguição da excelência e, acima de tudo, o alinhamento com as necessidades dos clientes devem ser considerados.

A definição da visão estratégica pode ser feita através de técnicas tradicionais c.e planejamento, mas a análise do posicionamento da organização no mercado, que significa conhecer em profundidade o ambiente em que ela está inserida deve ser feita, no nosso modelo, através da implantação de "um modelo de Inteligência Competitiva” (Fuld, 1993).

Inteligência Competitiva é um processo sistemático e ético de coleta de informações das atividades desenvolvidas pelos concorrentes e das tendências gerais dos ambientes de negócios. Ela deve ser sistemática. De nada adianta montar uma estrutura de coleta de informações sobre o ambiente de negócios, gerar os primeiros relatórios para, em seguida, paralisar esta atividade. Da mesma forma, um método deve ser estabelecido e mantido desde o início até o fim da atividade. Além disso, o processo deve ser ético, para preservar a imagem da empresa entre as concorrentes e os clientes.

Em resumo, um sistema de Inteligência Competitiva deve ser composto por um mínimo de quatro fases:

Identificação da informação necessária; Coleta; Análise e, principalmente, a Transmissão dessa informação aos tomadores de decisão.

Para a realização deste trabalho, levamos em consideração variáveis de ordem política, social, econômica e tecnológica. Para cada uma destas variáveis, consideramos o conjunto de atores presentes e concorrentes no ambiente de negócios.

Monitorar o ambiente externo à empresa, através da
Inteligência Competitiva é, no entanto, uma condição necessária, mas insuficiente para o hom desempenho das organizações na Sociedade do Conhecimento. O conjunto ambiente externo/ambiente interno da empresa tem que estar em perfeita sintonia com os objetivos dos negócios da empresa para que ela possa ganhar, com este monitoramento, vantagem competitiva. Este acompanhamento só é possível se a empresa e seus integrantes, estiverem cientes e comprometidos com a visão estratégica da empresa/organização.

\subsubsection{Capital Intelectual}

Em nosso entender, o conceito "capital intelectual" refere-se tanto à capacidade, habilidade e experiência quanto ao Conhecimento formal que os integrantes detêm e que agregam a uma empresa. O capital intelectual não é, entretanto, propriedade das empresas. As pessoas não são "patrimoniáveis". Na verdade, elas não pertencem às organizações desde, pelo menos, o fim da escravidão. Muito menos o capital intelectual destas pessoas. O “capital intelectual" é um ativo intangível que pertence ao próprio indivíduo mas que pode ser utilizado pela empresa para gerar valor.

Todos nós estamos acostumados a pensar nos funcionários de uma empresa em termos de quanto eles ganham ou, pior, de quanto eles custam. As perguntas deveriam ser: qual é o seu valor? Quanto as competências, habilidades e experiências desta pessoa agregam em valor para a organização? O que estamos queremos significar é que o mais importante é saber como este capital intelectual pode produzir em valor para a empresa.

Para captar, desenvolver e reter este capital intelectual, as empresa devem, inicialmente, definir suas competências essenciais. Essas competências são definidas como o conjunto de habilidades e tecnologias que permite à organização oferecer benefícios ao cliente. As habilidades que constituem essas competências são encontradas nos funcionários e somente através do desenvolvimento e estímulo dessas habilidades individuais a organização pode 
garantir que o negócio continue.

Em seguida, a organização deve partir para captar no mercado de trabalho os talentos que melhor se adeqüem às competências essenciais dessa organização. Ins- trumentos como mapeamento de habilidades individuais são usados para auxiliar nesta busca.

Finalmente, o desenvolvimento desse capital intelectual é feito através da implantação de fóruns de discussão e comunidades de prática, onde os funcionários das organizações compartilham suas experiências e Conhecimentos. Entretanto, somente captar e desenvolver o capital intelectual não agrega valor a/à organização: é necessário retê-lo. Para isso as empresas devem criar ambientes de trabalho agradáveis e estimulantes, promover uma gestão participativa e oferecer programas de participação nos lucros.

\subsubsection{Capital Estrutural}

O capital estrutural pode ser definido como um conjunto de sistemas administrativos, conceitos, modelos, rotinas, marcas, patentes e sistemas de informática, que permitem à organização funcionar de maneira efetiva e eficaz. Faz parte do capital estrutural a cultura da organi$z a c ̧ a \tilde{o}$, ou, em outras palavras, a maneira como uma determinada organização faz funcionar o seu negócio. De uma maneira simplista mas extremamente clara, Leif Edvinsson (1998) define o capital estrutural como "tudo aquilo que fica na organização quando as pessoas deixam o escritório e vão embora para casa”...

Se entrarmos numa loja do McDonald's no Rio, em Paris, Tóquio ou Moscou encontraremos sempre o mesmo lay-out de loja, o mesmo tipo de equipamentos, o mesmo sorriso dos funcionários, o mesmo tipo de atendimento e, se atravessarmos o balcão, veremos que todas as lojas devem preencher o mesmo tipo de relatório financeiro e se utilizam dos mesmos sistemas de Informática.

O capital estrutural, ao contrário do capital intelectual, pode ser criado pelos funcionários, mas pertence à organização.. De todos os capitais, o capital estrutural é o mais fácil de mensurar, pois geralmente sabemos quanto custa um determinado software ou uma determinada patente.

No nosso entender a gestão do capital estrutural deve contemplar três processos distintos e complementares. A definição do conjunto de processos - chave do negócio, a definição do tipo de estrutura organizacional e a definição dos instrumentos de acompanhamento e avaliação dos projetos (instrumentos de gestão) a serem utilizados.

\subsubsection{Capital de Relacionamento}

Para nós, capital de relacionamento é definido como a rede de relacionamentos de uma organização e seus colaboradores com seus clientes, fornecedores e parceiros. Concordamos com Allee (2000), quando ela diz que "no universo dos negócios, as redes são compostas de conjuntos de ligações dinâmicas entre diversos parceiros, os quais estão engajados em trocas deliberadas e estratégicas de serviço, Conhecimento e valor".

Os clientes são parte fundamental dos relacionamentos de uma empresa. Como diria Stewart (1998) "Entre as três grandes categorias de ativos intelectuais - capitais humano, estrutural e do cliente - os clientes são os mais valiosos. Eles pagam as contas".

O Capital de Relacionamento, portanto, é aquele que valoriza e incentiva uma empresa a estabelecer alianças estratégicas para ampliar sua presença no Mercado. Uma empresa isolada terá menores chances de obter/alcançar sucesso. Esses relacionamentos, individuais ou institucionais, possuem valor e devem ser gerenciados.

A partir da sua visão estratégica a empresa deve determinar os relacionamentos - chave para o sucesso de seu negócio - e construir uma estratégia de relacionamento com cada um deles. Existem clientes que dão retorno financeiro, outros que dão retorno de imagem e existem, ainda, aqueles que cobram qualidade nos serviços e produtos fornecidos. Eles, às vezes, não agregam valor econômico nem de imagem, mas são importantes para a empresa manter seus altos padrões de qualidade. 
4.3 Sinergia entre os Capitais

Já ressaltamos que a sinergia entre Conhecimento, inovação e empreendedorismo, definido como Inteligência Empresarial, é imprescindível para o sucesso das organizações na Sociedade do Conhecimento. Já enfocamos a importância da gestão dos capitais do Conhecimento: capital ambiental, capital estrutural, capital intelectual e capital de relacionamento. A interação entre esses capitais é a fonte de riqueza das organizações: é "o mapa da mina!"

Basta darmos um exemplo da importância desta integração entre os capitais do Conhecimento. De que adianta uma organização dispor de excelentes profissionais, com alto capital intelectual, se não dispuser de um mínimo de capital estrutural? O capital intelectual não poderá se realizar na prática; não acontecerá. Basta imaginarmos o que seria de uma excelente orquestra onde os músicos não dispusessem de seus instrumentos...

Cada organização deve mapear os seus capitais e verificar como um capital pode contribuir para o crescimento do outro? ${ }^{7}$.

\section{E o Brasil ?}

Em estudo publicado em 1996, o Banco Mundial aponta os chamados "Mercados Emergentes": os países e regiões que terão aumentada sua participação no mercado mundial de bens e serviços. Por este estudo, a participação dos EUA, hoje perto de $40 \%$, cairia para menos de $30 \%$ em 2010; a Comunidade Européia veria sua participação se reduzir dos atuais $35 \%$ para cerca de $27 \%$; o Japão manteria sua participação atual - em torno de $15 \%$ - e os países/regiões emergentes seriam a Ásia (China e tigres asiáticos), América Latina e Países do Leste Europeu (figura 3).

No mesmo ano, o Institute for the Future ${ }^{8}$ apresentou suas projeções com relação às exportações americanas de bens intangíveis - software, patentes, royalties, serviços. Por este estudo, estas exportações saltariam dos cerca de $4 \%$, de 1998, para quase $25 \%$ já no ano 2000 (figura 4). Note-se que as exportações de produtos como aviões, computadores e robôs, não entram na contabilidade de produtos intangíveis, embora o seu valor seja dado, principalmente, pela tecnologia e Conhecimento embutidos nestes produtos. Se considerarmos o percentual de Conhecimento incorporado a estes produtos, a participação dos intangíveis na pauta de exportações americanas salta para $70 \%$ !

Estes números nos sugerem a seguinte pergunta: para quem os EUA pretendem exportar estes produtos intangíveis, intensivos em Conhecimento? A figura 3 nos sugere que os chamados mercados emergentes devem ser os mercados preferenciais para absorção destes produtos de alto valor agregado. O nosso papel estaria assim definido. Assim como na transição da sociedade agrícola para a sociedade industrial, no início deste século - o

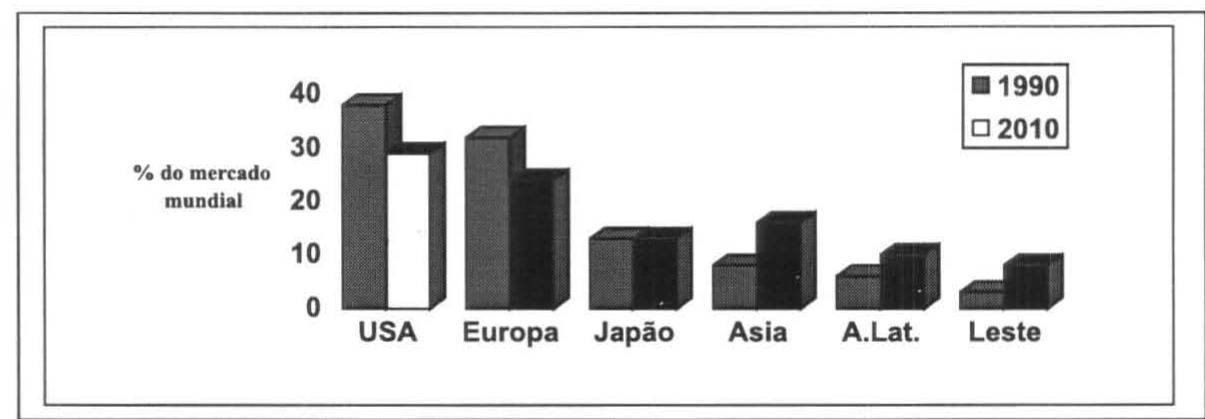

Fonte: Banco Mundial

Figura 3. Mercados Emergentes 


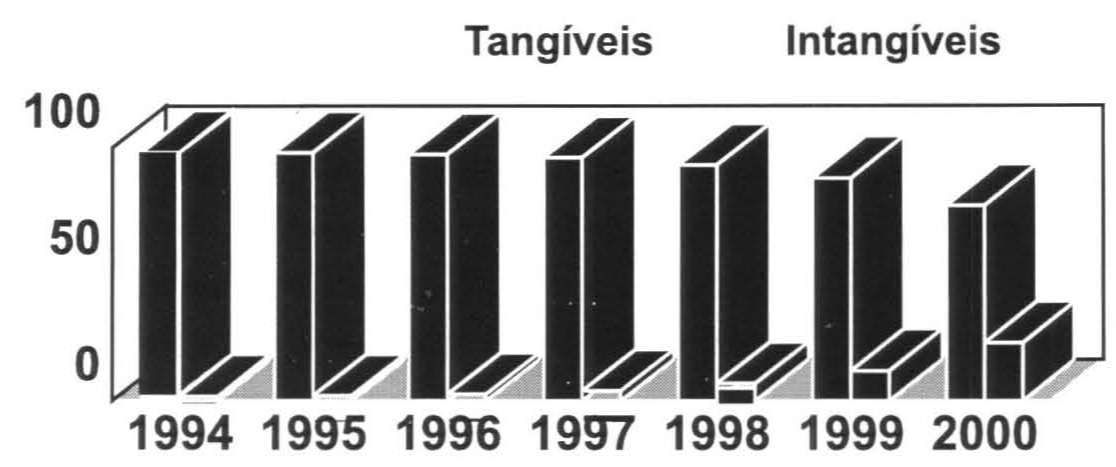

Fonte: Institute for the Future

Figura 4. Marcos Emergentes

Brasil era um grande produtor e exportador de café - nesta transição da sociedade industrial para a sociedade do Conhecimento, o papel que nos é reservado seria o de mero produtor de produtos industriais e importador de produtos intensivos em Conhecimento.

Será que estamos, mais uma vez, condenados a ocupar um papel de coadjuvante no cenário mundial? Devemos nos resignar com a opinião corrente de que o Brasil não tem condições de competir nas áreas e setores mais dinâmicos e de maior valor agregado?

Não temos esta opinião. Um momento de mudança paradigmática, como o que estamos vivendo, gera ameaças e cria oportunidades para todos os participantes do mercado. Empresas líderes de um segmento percebem que sua antiga forma vitoriosa de trabalhar não garante mais o sucesso. $\mathrm{O}$ uso inovador de novas tecnologias transforma empresas, que simplesmente não existiam há 6 anos atrás, em empresas líderes de mercado, como a Netscape ou a Amazon Books.

No Brasil, temos todos os elementos para um Ambiente de Inovação (nos moldes dos Sistemas Nacionais de Inovação): empreendedores, pesquisadores e/ou inventores, investidores e gestores de política. O que, então, nos deixa, geralmente, fora da competição nos negócios intensivos/abundantes em inovação e de alto crescimento?

Temos aqui, seguramente, um problema cultural que não temos a pretensão de abordar no âmbito deste artigo. Nossa cultura não valoriza o trabalho, embora a grande maioria da população trabalhe mais horas anuais que um trabalhador europeu ou americano. Pesquisa realizada em nossos cursos de graduação e pós-graduação na Escola de Engenharia de Produção da UFRJ, desde 1993, revelou que entre os valores "Trabalho", "Lazer", "Dinheiro" e "Saúde", os preferidos, pela ordem, são: Saúde, Dinheiro, Lazer e Trabalho ${ }^{9}$. A mesma pesquisa, realizada com engenheiros recém formados nos EUA, Inglaterra, Alemanha e Japão, apresentou resultado inverso: em primeiro lugar veio o trabalho, depois o dinheiro, lazer e saúde.

Como afirmamos em nosso livro "Gestão.com: administrando empresas na sociedade do Conhecimento", "Um dos comentários que costumamos fazer sobre esta pesquisa é que podemos ficar ricos de um dia para outro se jogarmos e ganharmos sozinhos na loteria. Não temos informação de que isto possa acontecer com um país. A ONU ainda não inventou uma loteria na qual um país pobre pudesse jogar e, ganhando-a, se transformar num país rico da noite para o dia. A receita é clara e a pesquisa nos 4 países desenvolvidos indicou: trabalho. Se a Alemanha e o Japão tivessem, como nós, o trabalho na parte mais baixa de sua escala de valores não conseguiriam reerguer seus países devastados por duas guerras mundiais". 


\section{Conclusão}

O Conhecimento, como aquele incorporado nos seres humanos ("capital intelectual") e na tecnologia, sempre foi central para o desenvolvimento econômico. Mas apenas nos últimos anos, quando as atividades econômicas tornaram-se mais e mais intensivas/abundantes em Conhecimento, sua importância relativa foi reconhecida. Investimentos em Conhecimento, tais como pesquisa e desenvolvimento, educação e treinamento, e abordagens inovadoras para o trabalho são consideradas a chave para o crescimento econômico

Neste artigo, procuramos apresentar algumas idéias para um debate que não podemos mais adiar. Mostramos a necessidade de se criar um novo modelo econômico que se baseie no fato de que o Conhecimento é o fator de produção essencial nessa nova Economia e propusemos um novo modelo de negócios para a Sociedade do Conhecimento: a Inteligência Empresarial. Este novo modelo se consubstancia no tripé Conhecimento, inovação e empreendedorismo.

Para a gestão do Conhecimento propomos o modelo dos Capitais do Conhecimento, que considera a gestão interna (capital estrutural, capital de relacionamento e capital intelectual) e a gestão externa ou ambiental do Conhecimento (capital ambiental). Este modelo não se propõe a realizar mágicas ou transformar as organizações da noite para o dia. Ele aponta apenas um caminho a ser seguido por todas aquelas organizações que desejam ter sucesso na Sociedade do Conhecimento. Ele é uma trilha e não um trilho...

\section{Notas:}

${ }^{1}$ Dale Neef, The Knowledge Economy, ButterworthHeinemann, EUA, 1998.

${ }^{2} \mathrm{O}$ leitor interessado pelo assunto vai encontrar um ótimo review sobre o que é "Conhecimento" no excelente livro de Nonaka e Takeushi. Criação do Conhecimento na Empresa. Campus. 1999

${ }^{3}$ Nonaka vai chamar isto de Conhecimento tácito. Nonaka \& Takeuchi, Idem.

${ }^{4}$ Embora os trabalhos de Adam Smith sejam os mais reconhecidos, na realidade, o primeiro a definir os fatores de produção como terra, capital e trabalho foi o economista francês Jean Baptist Say (1767-1832), no seu livro Cours d'Economie Politique, que possui uma edição pela Flammarion em 1996.

${ }^{5}$ OECD economic outlook. OECD (Organização para a Cooperação e Desenvolvimento Econômico), Paris, 1998.

${ }^{6}$ Os leitores poderão ler mais sobre o assunto no livro Gestão.com: administrando empresas na sociedade do Conhecimento, a ser lançado pela Editora Campus em outubro de 2000.

${ }^{7}$ http:Nwww.iftf.org

${ }^{8}$ Pesquisa realizada com 480 estudantes formandos em engenharia de produção entre 1993 e 1999.

\section{Referências Bibliográficas}

DAVENPORT, Thomas H., ECCLES, Robert G. and PRUSAK, Laurence. Information Politics. Sloan Management Review 34, no. 2, 1992.

DRUCKER, P. Post-capitalist Society, ButterworthHeinemann. ISBN 0-7506-2025-0, 1993.

HAMEL, Gary and. PRAHALAD, C. K. Competing for the Future. Boston, MA: Harvard Business School Press, 1994. 
MINTZBERG, Henry, RAISINGHANI, Duru and

THEORET, Andre. The Structure of "Unstructured"

Decision Processes, USA, Press Books, 1976.

NONAKA, Ikujiro and TAKEUCHI, Hirotaka. Criação de

Conhecimento na Empresa: Como as empresas

Japonesas geram a dinâmica da Inovação, Rio de

Janeiro, Campus, 1997.

POLANYI, Michael. The Tacit Dimension. London, UK:

Routledge \& Kegan Paul, 1966.

SCHEIN, Edgar H. Organizational Culture and

Leadership. San Francisco, CA: Jossey-Bass, 1985.

SENGE, Peter M. et al. The Fifth Discipline Fieldbook:

USA, 1994.

CASTELS, M. A Sociedade em Rede. São Paulo: Editora Paz e Terra, 1999.

SAY, Jean Baptiste. Cours d'Economie Politique, Paris:

Flammarion, 1996.

EDVINSSON, L., Capital Intelectual: descobrindo o valor real de sua empresa pela identificação de seus valores internos. Rio de Janeiro: Makron Books, 1998.

SVEIBY, K., A Nova Riqueza das Organizações, Campus, 1998.

STEWART, T. Capital Intelectual. Campus,1998.

ALLEE, V., Novas Ferramentas para uma Nova

Economia, Revista Inteligência Empresarial, número 3, abril de 2000 .

FULD, Leonard., Administrando a Concorrência, Rio de Janeiro: Record, ,1993. $2^{\circ}$ ed. 